\title{
Blockchain applications within the public sector: evidence from an international census
}

\author{
Giulia Maragno \\ Department of Management, Economics, and Industrial \\ Engineering, Politecnico di Milano, Via Raffaele \\ Lambruschini 4/b, 20156 Milan, Italy \\ giulia.maragno@polimi.it \\ Luca Tangi \\ Department of Management, Economics, and Industrial \\ Engineering, Politecnico di Milano, Via Raffaele \\ Lambruschini 4/b, 20156 Milan, Italy \\ luca.tangi@polimi.it
}

\begin{abstract}
The attention around blockchain in the public sphere is constantly increasing together with the expectations around its potentialities. Existing studies are mainly focused on technical elements or on a conceptual level of analysis. However, blockchain applications are starting to appear and be adopted by public organizations. Hence is now time for scholars to make a step forward, i.e moving from a theoretical level to a practical one, observing, studying, and analysing concrete existing solutions. This exploratory study aims at supporting scholars in doing this step. With a systematic analysis of secondary sources, it maps the current ecosystem of blockchain applications within the public sector, to identify the state-of-theart worldwide and the main trends and features that characterize blockchain implementation.
\end{abstract}

\section{CCS CONCEPTS}

- Applied computing $\rightarrow$ Computers in other domains; Computing in government; E-government.

\section{KEYWORDS}

Blockchain, public organizations, applications, international census

\section{ACM Reference Format:}

Giulia Maragno, Luca Gastaldi, Luca Tangi, and Michele Benedetti. 2021. Blockchain applications within the public sector: evidence from an international census. In DG.O2021: The 22nd Annual International Conference on Digital Government Research (DG.O'21), June 09-11, 2021, Omaha, NE, USA. ACM, New York, NY, USA, 10 pages. https://doi.org/10.1145/3463677.3463699

Permission to make digital or hard copies of all or part of this work for personal or classroom use is granted without fee provided that copies are not made or distributed for profit or commercial advantage and that copies bear this notice and the full citation on the first page. Copyrights for components of this work owned by others than ACM must be honored. Abstracting with credit is permitted. To copy otherwise, or republish, to post on servers or to redistribute to lists, requires prior specific permission and/or a fee. Request permissions from permissions@acm.org.

DG.O'21, fune 09-11, 2021, Omaha, NE, USA

(C) 2021 Association for Computing Machinery.

ACM ISBN 978-1-4503-8492-6/21/06 ..\$15.00

https://doi.org/10.1145/3463677.3463699

\author{
Luca Gastaldi \\ Department of Management, Economics, and Industrial \\ Engineering, Politecnico di Milano, Via Raffaele \\ Lambruschini 4/b, 20156 Milan, Italy \\ luca.gastaldi@polimi.it \\ Michele Benedetti \\ Department of Management, Economics, and Industrial \\ Engineering, Politecnico di Milano, Via Raffaele \\ Lambruschini 4/b, 20156 Milan, Italy \\ michele.benedetti@polimi.it
}

\section{INTRODUCTION}

Digital transformation has become a key issue and, nowadays, it is difficult to imagine any area of the society not affected by the introduction of digital technologies: thus, as Gil-Garcia et al. [1] point out, the public sphere is also involved. Indeed, in recent years the implementation of digital technologies has become a key objective in the political agendas and governmental strategic programmes [2], leading to the concept of digital government.

Among others, the interest around blockchain technology, which belongs to the family of Distributed Ledger Technology (DLT) and is mostly known thanks to the diffusion of digitalised currency payments, is gaining momentum. However, the adoption and the potentialities of blockchain - a distributed and decentralized ledger solution that gathers data and transactions, recorded and confirmed by the nodes of the chain - go beyond crypto-currencies and organizations from different industries are demonstrating a growing interest in the benefits it is supposed to yield [3]. According to Huumo et al. [4], the reason behind this rising attention is one of the main features of the technology. Blockchain enables data integrity, thus allowing its applications in every environment that requires transactions.

Despite the general hype, blockchain adoption opens several challenges [5] and issues [4] and, from a preliminary analysis of the literature, it appears that there is a general lacking of knowledge regarding its applications [6, 7].

The public sector has been and will be affected by blockchain applications. Due to the novelty of the phenomenon, so far the majority of the studies focused on a theoretical level and propose conceptual frameworks [8]. However, public organizations are now in a transition phase and some blockchain projects are already implemented. Hence, is time for scholars to make a step forward and place empirical evidence side by side with theoretical and technical reflections.

This exploratory study aims at supporting this transition. In particular, it maps the current ecosystem of blockchain applications within the public sector, to identify the international state-of-the-art of initiatives and to point out the main trends and features which characterize blockchain projects, setting the ground for future studies. This objective responds to Ølnes et al. [9] call to action to assess the range of blockchain initiatives in governments. The subsequent 
research questions are here addressed: Which are the potential applications of blockchain and Distributed Ledger Technology in the public sector? Which are the main feature of blockchain application in the public sector?

The paper is structured as follows: in the next section, we start with a brief overview of blockchain implementations within public organizations. In Section 3 we present the methodology adopted for data gathering and mapping the projects and then (Section 4) the findings of the study are discussed. The research ends with the conclusions and limitations of the study.

\section{BLOCKCHAIN IN PUBLIC ORGANIZATIONS}

Blockchain is frequently described as a potentially disrupting technology for organizations [10]: it can reduce transaction costs, generate distributed trust, and empower decentralized platforms [11, 12].

This technology is commonly related to crypto-currency, also due to the paper [13] published in 2008, where the unidentified Satoshi Nakamoto presented a peer-to-peer electronic cash system "based on cryptographic proof instead of trust, allowing any two willing parties to transact directly with each other without the need for a trusted third party". Thus the introduction of Bitcoin and, above all, of the underlying idea was disrupting: for the first time, value could be transferred between distant, untrusting parties without the need of an intermediary $[14,15]$.

Since then, it evolved and its applications went well beyond crypto-currencies [11]: The Economist, in October 2015, defined blockchain as a "trust machine", shifting the attention from cryptocurrencies to the technology and its application to different industries. The adoption of blockchain solutions has thus increased across various sectors [5] and also governments worldwide, spurred by the general hype and the potential benefits of blockchain adoption [9], started developing projects in different domains [16, 17].

The attention on blockchain in the public sphere is growing and according to Ølnes et al. [9], mentioning Swan [18], technology's features could enable a broad variety of processes, such as asset registry, information exchange, identity management, e-voting. The expectations concerning blockchain adoption in public organizations are high, also due to the key principles of the technology [19]:

- distributed database, thus every node of the chain can verify data and transactions;

- peer-to-peer transmission, meaning that a third, central node is not required for authorizing transactions;

- transparency with pseudonymity, thus transactions are visible to all the nodes and users can be anonymous;

- irreversibility of records, meaning that once data are recorded in the ledger they are immutable;

- computational logic, that allows users to set up algorithms that automatically cause transactions between nodes.

These features may be useful for the improvement of public services [8] and organizational processes [9].

In addition, the European Commission is laying the foundations for enhancing the implementation of blockchain solutions in the public sector, and many initiatives started to explore these applications, such as the European Blockchain Partnership and especially the European Blockchain Services Infrastructures (EBSI), the European peer-to-peer network of distributed nodes that will enhance cross-border digital public services.

In their analysis of blockchain diffusion in different industries, Grover et al. [20], adopting the model of the innovation-decision process proposed by Rogers et al. [21], point out that blockchain adoption in public settings is placed in the persuasion stage. This evidence is mirroring also academic research on the topic. Existing studies are mainly focused on its technical aspects and are proposing theoretical models [6]. Zein and Twinomurinzi in 2019 [22] show that half of the articles dealing with blockchain in the public sector has a theoretical focus, suggesting that it is still a nascent topic in academia.

However, from 2019 until now several steps forward have been done by public organizations and the topic cannot be considered anymore as 'nascent'. Some blockchain applications are starting to be in more advanced implementation phases or in few cases are starting to be already implemented in public settings. Hence, new paths for scholars are now open. The scientific community has shown a growing interest in blockchain adoption in public organizations, but very little operative researches are up and running. Along with the need to keep researching at a technical and theoretical level, qualitative and quantitative research that investigates blockchain applications in public settings needs to be conducted. For example, case studies shall be conducted for understanding possibly all aspects concerned with blockchain introduction in public affairs (for example barriers, drivers, benefits, organizational solutions). In this direction, for example, Ølnes et al. [9] assert that the academic literature identifies a diversity of benefits related to the adoption of blockchain, but frequently they are not supported by empirical evidence.

In order to do that an intermediate step is in our view missing. In fact, an overview of how and where blockchain is nowadays implemented in public settings is still missing and is needed. For example, in their literature review Batubara et al. [8] state that blockchain applications have been investigated with more attention in certain public domains - i.e. healthcare, education, and in the context of smart cities. However, no empirical studies so far confirmed this statement with quantitative data on blockchain projects.

This paper aims at filling this intermediate step, necessary for opening the path to empirical analysis on blockchain and, to our knowledge, still missing in academic literature. We made a census of 264 existing blockchain projects worldwide in the public sector; classifying them in several ways from the domain of application to the maturity stage and the geographical location.

\section{RESEARCH METHODOLOGY}

The blockchain and DLT applications documented have been gathered by an international census of news articles from sector-specific journals - e.g. CoinDesk, Reuters, The Cointelegraph - and they were classified in a database. The choice to rely on news articles was made because academic studies on blockchain adoption within public boundaries are still limited and little empirical evidence is provided. We considered these journals as the primary data source as, to the best of our knowledge, they provide an up-to-date and global picture of the evolution of blockchain and Distributed Ledger 
Technologies across different sectors. Moreover, the choice to examine also an Italian media platform was due to have insights on the state of the art of the project developed by the Italian public sector.

In addition to these sources, consultancy documents and reports published by the European Commission [16, 23, 24] and international bodies [17] have been analysed. Moreover, the map of the EU Blockchain Observatory and Forum has been used as a data source. An overview of the data sources used in the study is presented in Appendix A.

The study of news articles allowed us to conduct an exploratory analysis of the main features and challenges related to the use of blockchain and distributed ledger technologies in the public sector. The data gathered provide a first map of the development of blockchain applications among public organizations, however, the evidence should be further deepened and tested by adopting other methodologies. We began to collect news related to blockchain implementation starting from January 2017, due to the increasing interest in the technology, to the end of October 2020.

Blockchain projects considered for inclusion were those written in English and Italian and solutions related to the issuance of cryptocurrencies by central banks (Central Bank Digital Currency - CBDC) were not analysed since they are considered as market-related factors. The study resulted in gathering 264 unique applications and each application was input as an individual record in the database according to specific criteria defined with the researchers of the Blockchain and Distributed Ledger Observatory of Politecnico di Milano, a permanent research initiative that addresses the topic of blockchain and distributed ledger implementation among different sectors.

The taxonomy was developed in a cyclical process and we periodically share the projects mapped with the Blockchain and Distributed Ledger team for verifying the completeness and representativeness of the variables over time. Moreover, the framework of analysis was presented also during a workshop held in October 2019 to a group of more than 70 Italian practitioners - both public and private managers involved in the digital transformation of the public sector - who contributed in discussing and defining the dimensions used for the analysis.

The following dimensions have thus been adopted for mapping the projects:

- Public domain. To identify in which domain the technology is implemented, projects were categorized according to the Classification of the Functions of Government (COFOG) developed by OECD in 1999 and published by the United Nations Statistical Division. The classification has three levels of detail - divisions, groups, and classes. The first level of the classification (i.e. Divisions) identifies the general government expenditure in ten categories, according to their objective: general public services; defence; public order and safety; economic affairs; environmental protection; housing and community amenities; health; recreation, culture, and worship; education; social protection. The second and the third levels data report the means by which these intents are achieved.
- In this research, the authors apply as the lens of analysis the first dimension, thus considering the main goal of governments. The COFOG classification provides 10 divisions: we included an additional one for those projects that address more than one area. We decided to rely on the COFOG functional classification of government since it is well established in statistical research and also in the scientific community [25], [26].

- Stakeholder involved. To examine which typology of interaction the applications enhance, projects were classified considering the relations with three main groups of stakeholders: citizens; businesses; other public organizations, and civil servants.

- Process. To assess which government operations are impacted by blockchain implementation, the projects were classified considering 8 processes. To identify the taxonomy for processes' classification, we started from the analyses conducted by the Blockchain and Distributed Ledger Observatory and, after the reading of several reports and the coding of empirical data, we developed a specific taxonomy for the public sector and we identified the following processes:

- Data and document management, thus applications related to the storing of certifications and records exchange, such as academic or health data;

- E-voting, including all the projects concerning blockchain adoption in digital voting systems;

- Procurement, including, for instance, applications for the management of public contracts and tenders;

- Identity management, thus the applications related to blockchain improvement for the enhancement of digital identity management;

- Payments and tributes, namely those projects related to public payments and tax system;

- Property management, thus the projects implemented to support the transactions of physical assets, such as land titles, ensuring property registration;

- Logistic, thus the applications related to the traceability of products and resources.

As for the public domain variable, an additional process has been added for those projects that impact more than one process.

- Start year. To understand the trend of development over time, the data of news articles have been considered representative to frame the project development, regardless if it represents an intention of future development, the beginning of the experimentation phase or the operative phase.

- Level of maturity. In addition to the latter dimension, for each project the level of development was tracked to understand its stage of maturity. Blockchain and DLT applications were thus categorized following three levels: Announcement, thus applications that have not started yet, such as a declaration of intent about the developing of the project; Proof of Concept $(\mathrm{PoC})$, hence those projects whose phase of experimentation has already started; Operative, therefore those projects which are completely operational.

- Geographical distribution and project dissemination. Such criteria allowed to categorize the applications based on the 


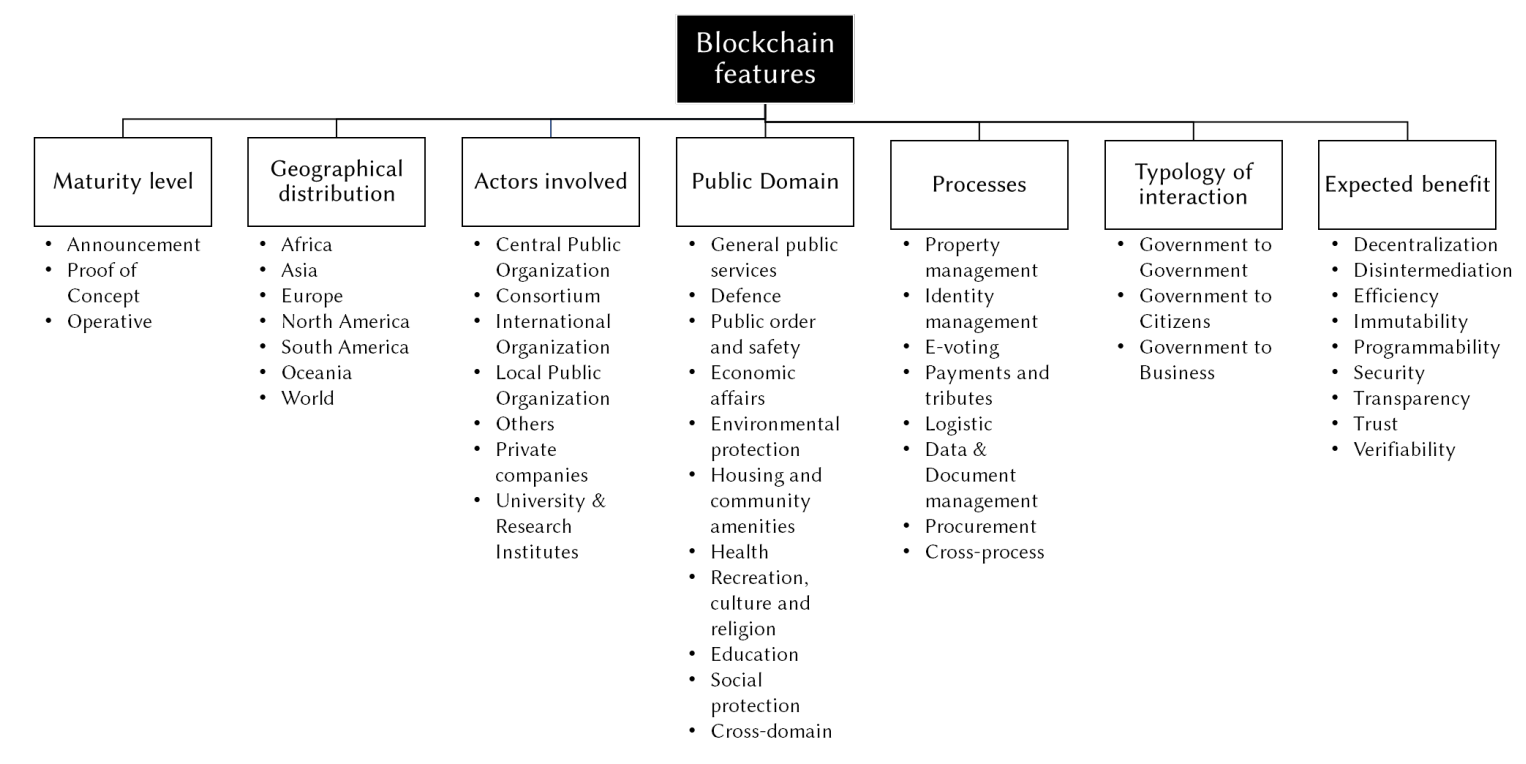

Figure 1: The analytical framework adopted to investigate blockchain applications

geographical area where they are being developed and the geographical extension they are expected to reach.

- Actors involved. To identify the public organizations more interested in blockchain development, we clustered the applications considering 7 actors: Central Public Organizations, Local Public Organizations, University, and Research Institutes, International Organizations, such as the NGOs or the European Commission, and Consortium, if the demand for the project is undertaken by more than one institution. The study reviews also the applications implemented by Private Companies in collaboration with public organizations and the solutions implemented by other actors, such as political parties, that go under the Others layer.

- Implementation goal. Since the technology is rather immature, it is difficult to talk about benefits obtained and to quantify them. The analysis thus considered the expected objectives of each project.

Figure 1 illustrates the variables used to study blockchain applications: in Section 4 we analyse the elements of the taxonomy and, for some of them, we performed a cross-case analysis to highlight the relation among the different variables of the analytical framework.

\section{FINDINGS}

This section is dedicated to the findings of the international census. The analysis aims to map the use cases of blockchain and DLT implemented by public organizations worldwide to find the main trends of their adoption. The details of each criterion of analysis have been explained in the previous section.

\subsection{Blockchain evolution trend and maturity level}

The analysis highlights that blockchain applications in public settings have constantly increased over the last four years: from 30 in 2017 to 264 on a cumulative basis in 2020 . However, as shown in Figure 2, in the last year there has been a setback, with a decrease $(-58 \%)$ of the number of projects. The significant fall is mainly due to the reduction of the implementations in the announcement stage, whereas the growth of projects in a pilot or operative stage remains rather stable.

These data show that the majority of the applications are still at the announcement phase (160 projects; $61 \%$ ), confirming what the literature points out: the technology is gaining momentum in the public context, but its level of adoption is at its early stage.

\subsection{Geographical distribution analysis}

Looking at the geographical distribution, the study considers the diffusion of blockchain applications in terms of continents and then, going more in detail, in terms of countries. As Figure 3 depicts, the geographical diffusion of blockchain projects in the public context is pretty homogenous among Asia (88 projects; 33\%), Europe (81 projects; $31 \%$ ), and North America (57 projects; $22 \%$ ). The remaining 38 projects $(14 \%)$ are spread among South America, Oceania, Africa or have a worldwide diffusion.

Finally, regarding the geographical expansion, most of the applications (125) have national dissemination, followed by the city (52) and territorial diffusion (38).

\subsection{Blockchain applications per actors involved}

To identify the public demand of blockchain applications, the analysis focuses on the actors involved in the experimentations. As 


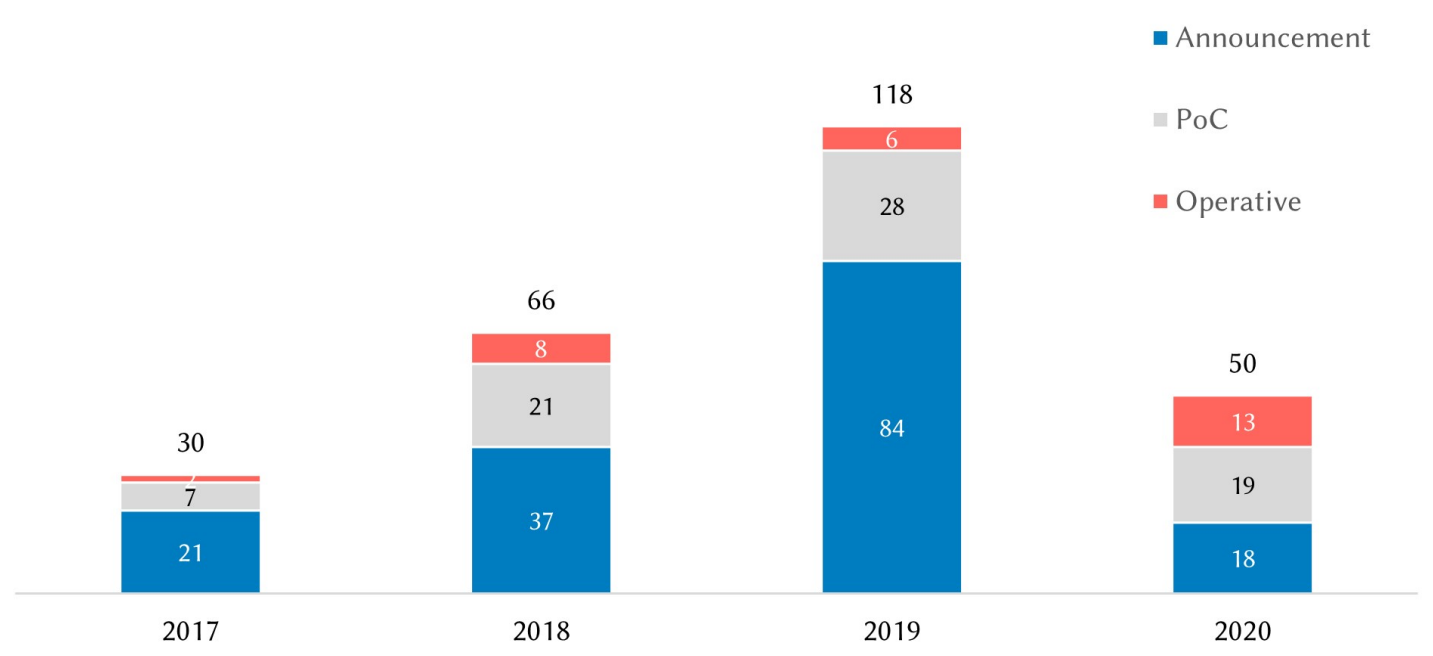

Figure 2: Projects distribution by starting year and maturity level

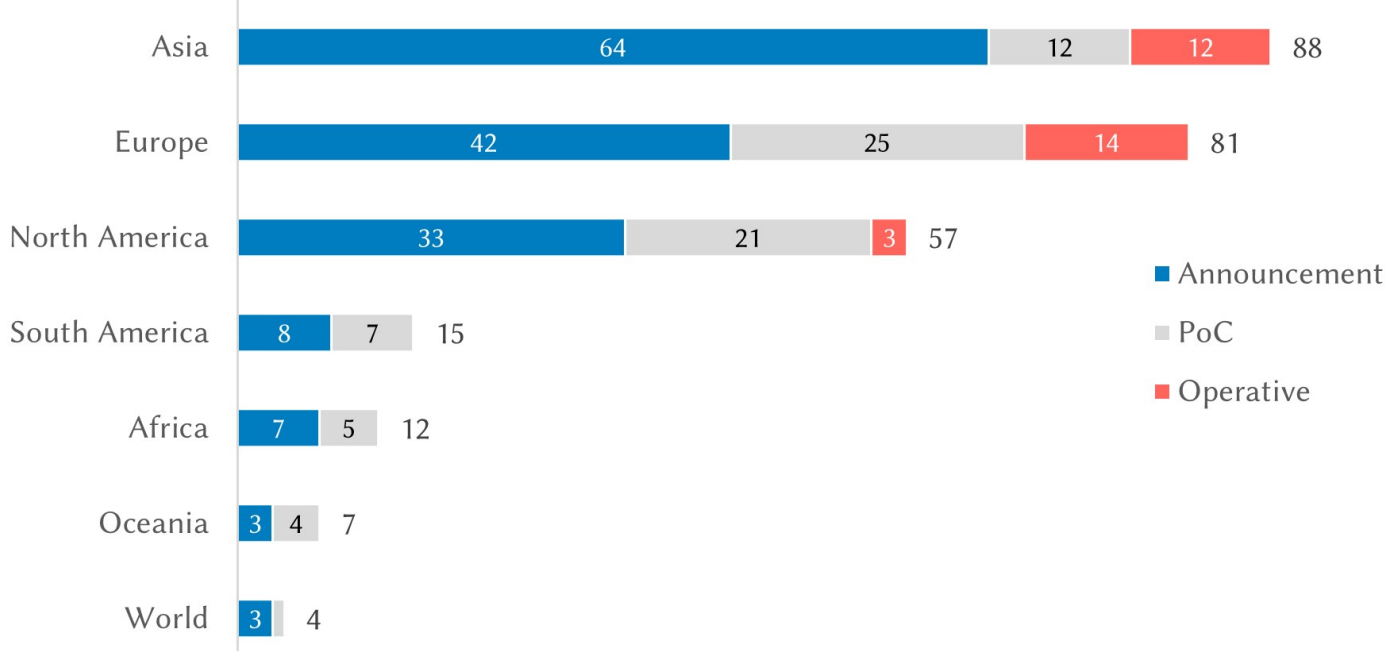

Figure 3: Projects distribution by geography and maturity level

depicts in Figure 4, Central Public Organizations are the institutions that show the highest demand of projects (122). Concerning the other actors, Local Public Organizations (69 projects) and University and Research Institutes (21 cases) follow. It is interesting to note the role of partnerships both between public and private actors: the applications mapped show that the collaboration between different typologies of organizations is a possible way to propose and develop blockchain applications, leading at the moment to 16 solutions. Lastly, the census indicates that also private companies are interested in blockchain applications in the public sphere.
Then, a cross-data analysis was performed to compare the breakdown of the projects in terms of maturity level between the most interesting institutions, namely Central and Local Public Organizations.

The evidence that emerged from the census highlights that the percentage of operative applications out of total projects changes for each category. More in detail, in the Central Public Organizations cluster, 12 out of 122 are operative (i.e. $10 \%$ of their projects), while Local institutions have 11 out of 69 projects operative (i.e. 16\%). Hence, according to the analysis of the census, the latter, despite 


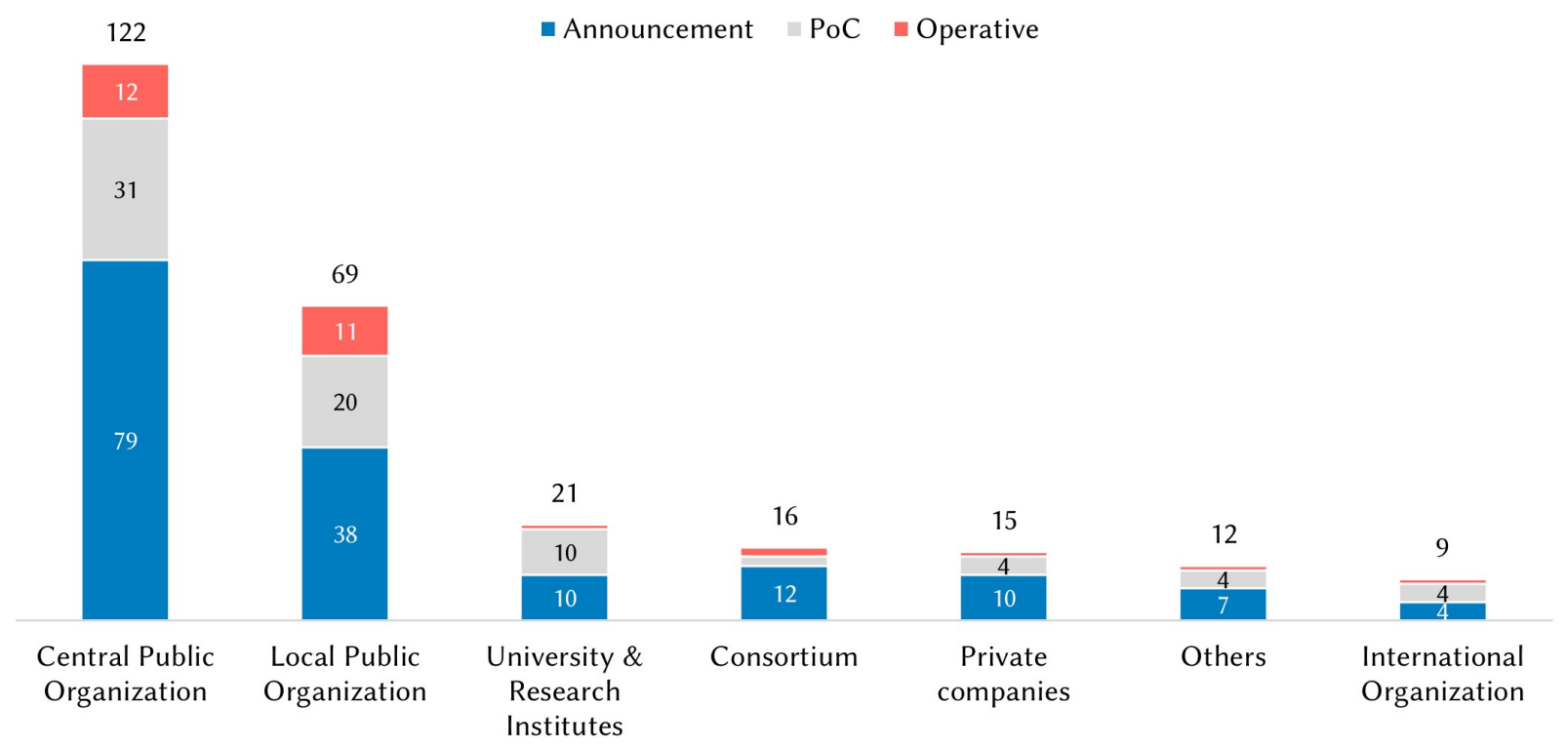

Figure 4: Blockchain applications per actors and maturity level

a lower development of blockchain applications, seems to have a higher conversion ratio of initiatives.

\subsection{Blockchain applications: a cross-data analysis among processes and domains}

Following the COFOG classification, the public domains in which blockchain applications are implemented have been investigated. Among the highly explored application areas, General Public Services stands out with 81 projects $(31 \%)$. Other significant domains are Economic Affairs, with 50 applications (19\%), and the Health sector with 37 applications (14\%). Turning to the process distribution, most of the blockchain applications examined in this study are adopted to support Data and document management (102; 39\%), followed by applications that support the traceability of products (35; 13\%). Then, projects related to digital voting system and digital identity management count respectively 28 applications (11\%).

As mentioned before (Section 3), both for the domain and the process criteria an additional group has been added: applications for which it was not possible to identify a single domain or process were marked as Cross-domain or Cross-process. Then, as Figure 5 depicts, blockchain applications have been classified cross-checking data related to their level of maturity, public domains, and processes. This matrix allows to better identify which are the main processes for each domain and provides an overall view of the technology adoption.

Through the cross-data analysis, we were able to shed light on the areas where the majority of the blockchain applications are developed. Indeed, 6 relevant combinations emerged:

1. Data and Document Management processes in the Health division: 26 applications have been surveyed, among which 6 are in the pilot phase and 4 in an operative stage. The applications in this category concern the digitalization and the exchange of medical documents in a secure way across multiple actors through a distributed ledger rather than a traditional registry.

2. Data and Document Management processes in the Education area: 27 applications have been identified, of which 9 are Proof of Concept projects and 4 operatives. The applications regard the digitalisation and storing of academic certificates, creating secure and immutable registries where documents are recorded.

3. Logistic processes in the Economic Affairs domain: 21 applications have been identified, of which 6 are in the Proof of Concept phase and 3 in an operative stage. The applications in this domain are related to the traceability of products and resources: for instance, blockchain-based applications are developed to ensure the security of drugs or food supply chains.

4. E-Voting process in General Public Service application area: 19 applications have been detected, among which 8 are in the Proof of Concept phase and 2 are already operative. The applications are related to the implementation of a blockchainbased online voting mechanism.

5. Identity management process in General Public Service domain: 21 applications have been surveyed, of which 6 are pilots and 3 operative applications. The projects regard the adoption of blockchain-based systems to enhance the provision of digital identity.

6. Property Management processes in Housing and community amenities domain: 20 applications have been detected, of which 5 are in the Proof of Concept phase and 3 in the operative stage. Applications in this field are related to the creation of immutable registries, where the property of assets is registered. Among the projects analysed, it emerged that 


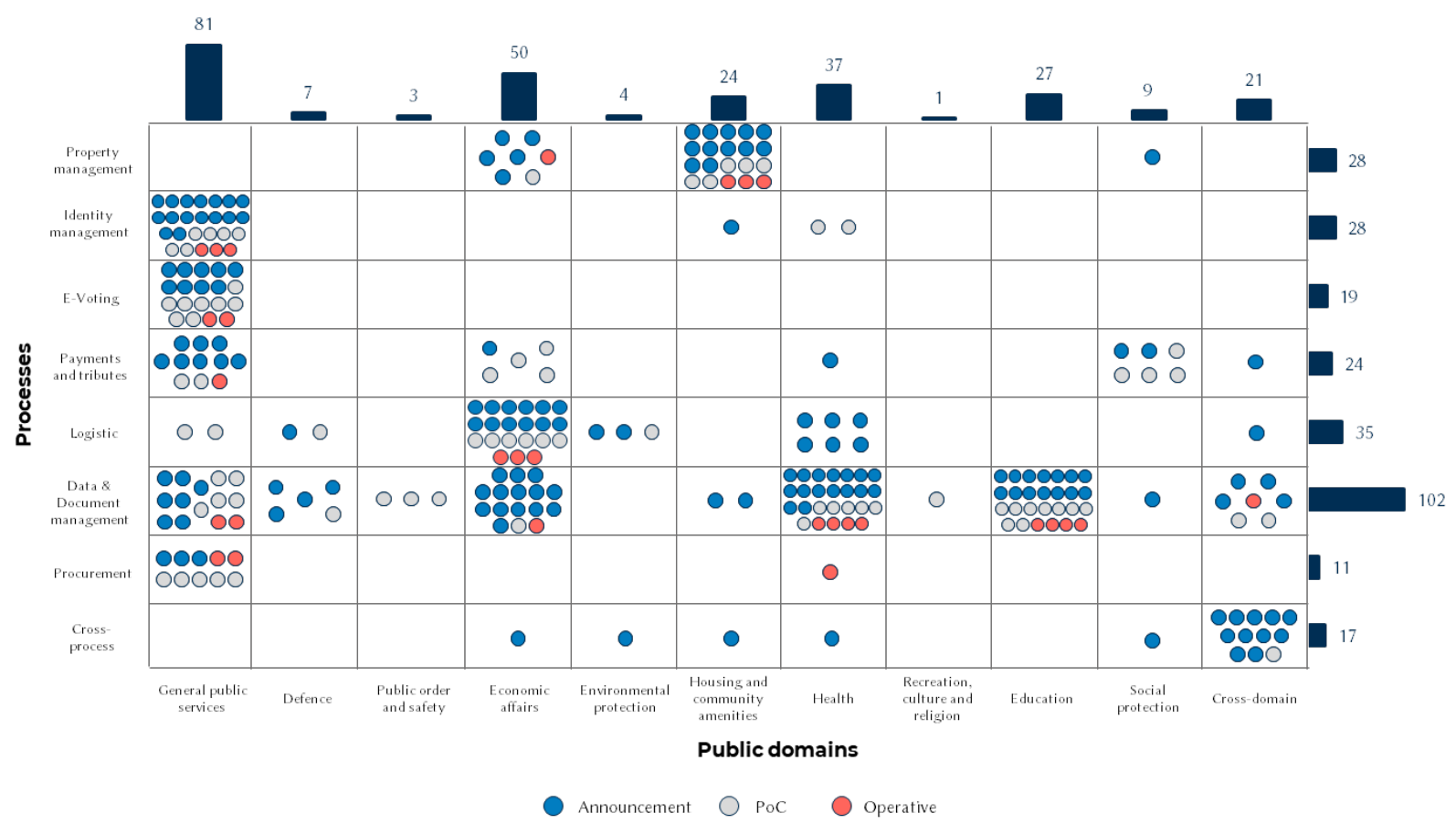

Figure 5: Blockchain applications per processes and public domains

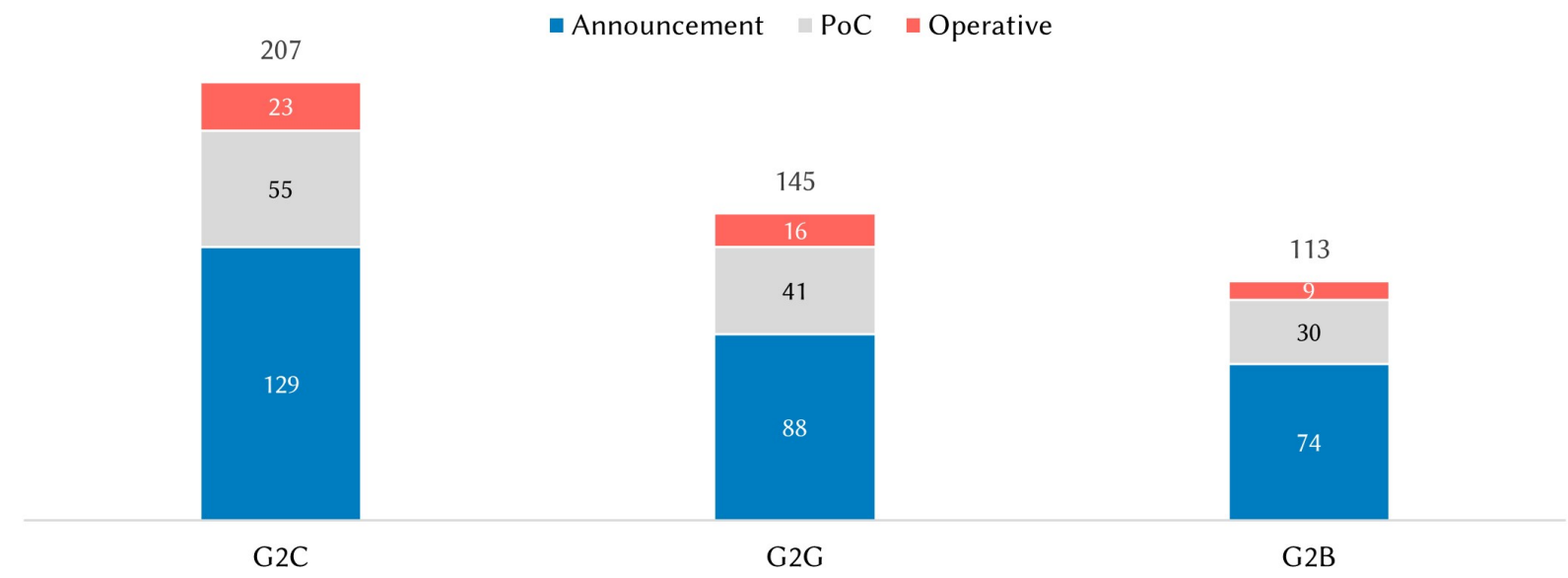

Figure 6: Blockchain applications per typology of interaction and maturity level

blockchain applications are implemented mainly for land registry, intellectual property records, and vehicle registry.

\subsection{Blockchain applications: stakeholder analysis}

With regards to the typology of interaction that blockchain applications enhance, projects were classified considering the relations with three main groups of stakeholders: citizens; businesses; other public organizations, and civil servants. It is important to note that each application could address more than one group. From the analysis, it emerges that most of the applications (207) are developed to improve the interaction between government and citizens (G2C). As Figure 6 outlines, a more limited part of the projects is developed to improve the internal functioning of public organizations $(\mathrm{G} 2 \mathrm{G}$; 145 out of 264) or to optimize the relationship with business (G2B; 113). 


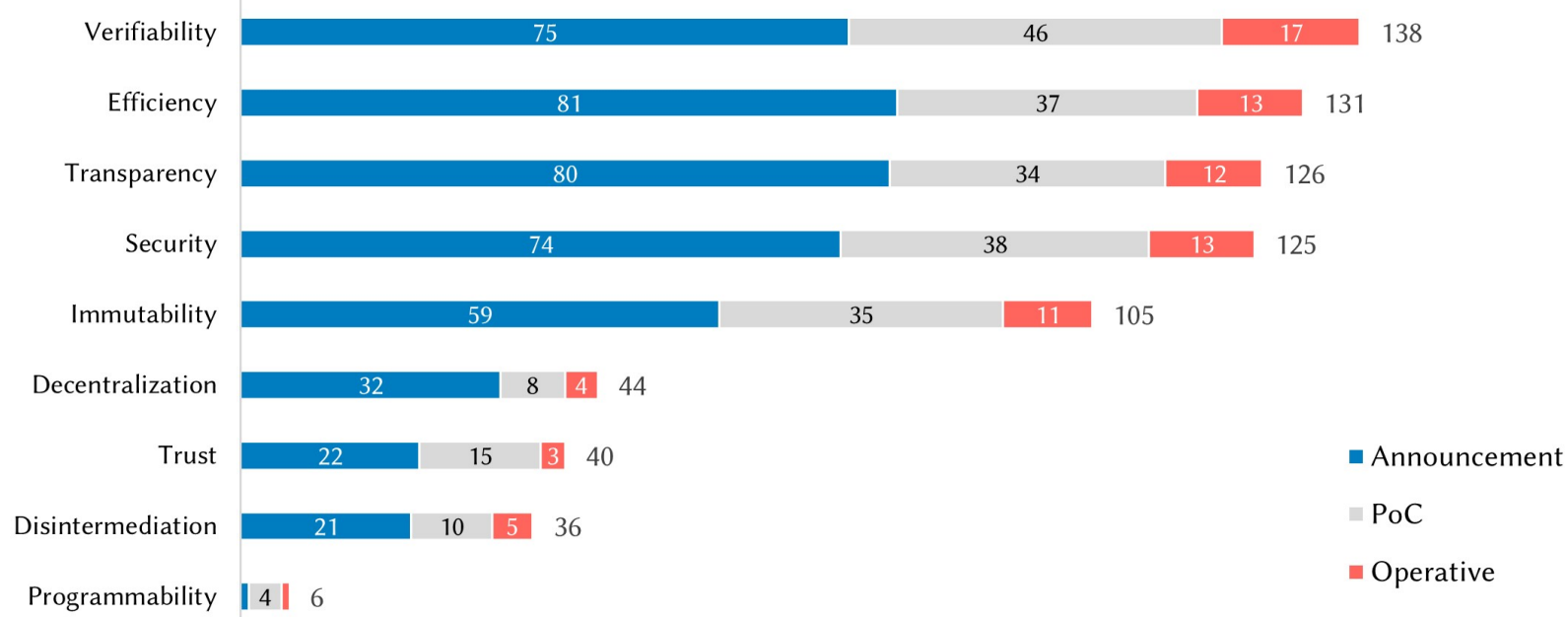

Figure 7: Blockchain expected outputs and maturity level

\subsection{Blockchain applications: expected outputs}

Since blockchain adoption within the public sector is rather in its earliest stages, it is difficult to talk about benefits obtained and quantify them. This study considers the expected objectives of each project, to deepen the main drivers that lead to the improvement of blockchain applications. As the bar chart in Figure 7 depicts, public organizations implement blockchain projects to reach several objectives, but mainly to enhance verifiability, efficiency, and transparency. Each project could address more than one goal.

\section{CONCLUSIONS AND LIMITATIONS}

The interest of both academics and practitioners around blockchain in the public context is constantly growing in the last few years. The relevant number of blockchain applications detected with the analysis confirms this evidence.

Nevertheless, the research outlines that, even if there are great expectations around this technology, its adoption is rather in the earliest stages. The majority of the projects are still at the announcement phase, however, some exceptional cases of blockchain projects already operative can be found. This result shows on one hand how the technology is gaining momentum within public organizations and, on the other, how public institutions still lack understanding of how to leverage their capacity to convert announcements into more mature projects. However, even if the last year has shown a significant decrease of applications, the growth of pilot and operative projects stays constant, indicating that the adoption of blockchain and Distributed Ledger technologies within the public sector is slowly starting to stabilize.

All continents are looking at blockchain and Distributed Ledger Technologies, although Asia, Europe, and North America have more projects than the others. Moreover, some applications are implemented in cooperation between countries. This is probably due to specific call and founding activities that request worldwide partners. Blockchain applications in the public sector are mainly carried out by central public organizations, followed by local bodies: this is not surprising, as central institutions are frequently more organized and they could rely on enough human and financial resources that allow them to plan the implementation of blockchain applications. Correspondingly, the majority of the applications addresses national dissemination.

In terms of the application domain, most of the applications mapped are active in the General Public Service area and regarding the processes, the analysis shows that blockchain-based applications are implemented to support the management of data and documents.

Such data are consistent with the evidence that emerged from the analysis of the relations enhanced by blockchain-based applications: public organizations develop these projects mainly to implement the interaction with citizens.

To conclude, the study contributes to the knowledge of blockchain implementations within the public sector thanks to innovative inside on the spread of blockchain in public settings. Moreover, the methodology adopted, i.e. the collection of information from news articles, offers a new and innovative lens and helps the creation of a bridge between academia and practice. Especially now, when uncertainty on the potential of blockchain in public settings is high, academia and practice must cooperate and follow the same path, for supporting the growth in the usage of this technology in public affairs.

The research has several implications and recommendations for academia. First, it suggests to start collecting empirical evidence, filling an existent gap. It demonstrates that there are a lot of applications already developed or in development, hence there is a lot of empirical evidence that needs to be systematised, and that can bring to new knowledge on blockchain implementation. Second, it proposes a way for classifying blockchain applications that can be a basis for positioning future studies on blockchain. Third, it offers an overview of blockchain applications highlighting the current situation in blockchain applications worldwide. To the best of our knowledge, this paper is the first proposing census of blockchain applications within the public sector. Moreover, it opens a path for 
future studies for understating the reasons behind these differences for example in the expected outputs, or the affected processes and domains.

From a managerial and policy perspective, the research highlights the increasing interest of public organizations and provides public organizations with insights related to the main trends of blockchain implementation. Public managers shall be aware of the current trends in blockchain implementation in order to understand the main domain of application and intervene with specific policy at the national and/or local level for directing and guiding blockchain implementation.

The research project has some limitations. The first limitation concerns the database creation through a census of secondary sources. To build it, news articles from sector-specific journals have been examined: these sources have a margin of error and do not always provide sufficient details and insights on the maturity of the technology or the process of adoption. Future research could overcome this limitation, using this study as a starting point to select blockchain-based applications that could be investigated through case studies.

The second limitation regards the criteria adopted to select the projects: the study considers only news in English or Italian, with online openly available information. Therefore, even if the data-set provides a rather broad overview of the ecosystem of blockchain and DLT applications in the public context, the study omits those projects in other languages and for which information is not available online. Future research could shed light on these solutions, enlarging the current census.

\section{REFERENCES}

[1] J. R. Gil-Garcia, S. S. Dawes, and T. A. Pardo, "Digital government and public management research: finding the crossroads," Public Manag. Rev., vol. 20, no. 5, pp. 633-646, 2018

[2] J. R. Gil-García and T. A. Pardo, "E-government success factors: Mapping practical tools to theoretical foundations," Gov. Inf. Q., vol. 22, no. 2, pp. 187-216, 2005.

[3] L. Hughes, Y. K. Dwivedi, S. K. Misra, N. P. Rana, V. Raghavan, and V. Akella "Blockchain research, practice and policy: Applications, benefits, limitations, emerging research themes and research agenda," Int. f. Inf. Manage., vol. 49, no. February, pp. 114-129, 2019

[4] J. Yli-Huumo, D. Ko, S. Choi, S. Park, and K. Smolander, "Where is current research on Blockchain technology? - A systematic review," PLoS One, vol. 11, no. 10, pp.
$1-27,2016$

[5] M. Janssen, V. Weerakkody, E. Ismagilova, U. Sivarajah, and Z. Irani, "A framework for analysing blockchain technology adoption: Integrating institutional, market and technical factors," Int. 7. Inf. Manage., vol. 50, no. July 2019, pp. 302-309, 2020.

[6] M. Risius and K. Spohrer, "A Blockchain Research Framework: What We (don't) Know, Where We Go from Here, and How We Will Get There," Bus. Inf. Syst. Eng., vol. 59, no. 6, pp. 385-409, Dec. 2017

[7] J. Weking, M. Mandalenakis, A. Hein, S. Hermes, M. Böhm, and H. Krcmar, "The impact of blockchain technology on business models - a taxonomy and archetypal patterns," Electron. Mark., no. Lacity 2018, 2019.

[8] F. R. Batubara, J. Ubacht, and M. Janssen, "Challenges of blockchain technology adoption for e-government: A systematic literature review," ACM Int. Conf. Proceeding Ser., pp. 20-22, 2018.

[9] S. Ølnes, J. Ubacht, and M. Janssen, "Blockchain in government: Benefits and implications of distributed ledger technology for information sharing," Gov. Inf. Q., vol. 34, no. 3, pp. 355-364, 2017.

[10] K. Behnke and M. F. W. H. A. Janssen, "Boundary conditions for traceability in food supply chains using blockchain technology," Int. 7. Inf. Manage., vol. 52, no. March 2019, p. 101969, 2020.

[11] F. Hawlitschek, B. Notheisen, and T. Teubner, "The limits of trust-free systems: A literature review on blockchain technology and trust in the sharing economy," Electron. Commer. Res. Appl., vol. 29, pp. 50-63, 2018

[12] Y. Chen and C. Bellavitis, "Blockchain disruption and decentralized finance: The rise of decentralized business models," F. Bus. Ventur. Insights, vol. 13, 2020

[13] S. Nakamoto, "Bitcoin: a peer-to-peer electronic cash system, October 2008," Cited on, 2008.

[14] C. Catalini and J. S. Gans, "Some Simple Economics of the Blockchain," SSRN Electron. 7., 2016.

[15] E. D. Zamani and G. M. Giaglis, "With a little help from the miners: distributed ledger technology and market disintermediation," Ind. Manag. Data Syst., vol. 118, no. 3, pp. 637-652, 2018.

[16] D. Allessie, M. Sobolewski, L. Vaccari, and F. Pignatelli, Blockchain for digital government, vol. 29677. 2019.

[17] D. Fundation, "Bringing Blockchain Into Government."

[18] M. Swan, Blockchain: Blueprint for a new economy. 2015.

[19] M. Iansiti and K. R. Lakhani, "The truth about blockchain," Harv. Bus. Rev., vol. 2017, no. January-February, 2017.

[20] P. Grover, A. K. Kar, and M. Janssen, "Diffusion of blockchain technology: Insights from academic literature and social media analytics," f. Enterp. Inf. Manag., vol. 32 , no. 5, pp. 735-757, 2019.

[21] E. M. Rogers, A. Singhal, and M. M. Quinlan, Diffusion of innovations. 1983.

[22] Zein and Twinomurinzi, Towards Blockchain Technology to Support Digital Government, vol. 1. Springer International Publishing, 2019.

[23] T. Lyons, L. Courcelas, and K. Timsit, "FOR GOVERNMENT AND PUBLIC SERVICES," 2018.

[24] A. G. A. F. Camiller, Blockchain in Education Luxembourg: Publications Office of the European Union. 2017.

[25] G. Misuraca, C. van Noordt, and A. Boukli, "The use of AI in public services," pp. 90-99, 2020.

[26] W. G. de Sousa, E. R. P. de Melo, P. H. D. S. Bermejo, R. A. S. Farias, and A. O. Gomes, "How and where is artificial intelligence in the public sector going? A literature review and research agenda," Gov. Inf. Q., vol. 36, no. 4, p. 101392, 2019. 


\section{APPENDIX A- DATA SOURCES}

\section{Table 1: Data sources of the research}

\begin{tabular}{|c|c|c|}
\hline & Source & Brief description \\
\hline \multirow[t]{10}{*}{ Data source } & Asia Blockchain Review & $\begin{array}{l}\text { Media and community platform for Asia-centric projects and businesses. } \\
\text { The news depict the most prominent blockchain projects and developments } \\
\text { in the community around Asia }\end{array}$ \\
\hline & Blockchain 4Innovation & $\begin{array}{l}\text { Italian media platform providing information and knowledge on blockchain } \\
\text { adoption across all the business sectors }\end{array}$ \\
\hline & CoinDesk & $\begin{array}{l}\text { Media platform that covers the evolution of cryptocurrencies, digital assets } \\
\text { and the blockchain ecosystem }\end{array}$ \\
\hline & Cointelegraph & $\begin{array}{l}\text { Independent digital media resource reporting a wide range of information } \\
\text { related to blockchain technology, crypto assets, and emerging fintech trends }\end{array}$ \\
\hline & Cryptonomist & $\begin{array}{l}\text { Online newspaper with Italian and English news, related to the main } \\
\text { aspects of the crypto-economy }\end{array}$ \\
\hline & Decrypt & $\begin{array}{l}\text { Site focused on providing information and toolkits to recount and } \\
\text { understand the development of the decentralized web }\end{array}$ \\
\hline & $\begin{array}{l}\text { GCN / Technology, Tools and } \\
\text { Tactics for the Public Sector }\end{array}$ & $\begin{array}{l}\text { The Digital Edition provides technology assessments, recommendations, } \\
\text { and case studies to support Public Sector IT manager responsible for the } \\
\text { selection and development of technology solutions }\end{array}$ \\
\hline & Government Technology & $\begin{array}{l}\text { The magazine provides editorial contents about information technology in } \\
\text { the public sector, with a focus mainly on the state and local government }\end{array}$ \\
\hline & Ledger Insights & $\begin{array}{l}\text { The site publishes global news about business and enterprise blockchain. } \\
\text { The main focus is on enterprise, even if some articles concern also the } \\
\text { public sector }\end{array}$ \\
\hline & Reuters & $\begin{array}{l}\text { News agency providing information concerning historical and current } \\
\text { events, financial and business, technology, and government }\end{array}$ \\
\hline
\end{tabular}

